\title{
Digital management technology and its application to investment casting enterprises
}

\author{
Xiao-yuan Ji, Hu Ye, *Jian-xin Zhou, and Wei-lin Deng \\ State Key Laboratory of Materials Processing and Die \& Mould Technology, Huazhong University of Science \& Technology, Wuhan 430074, China
}

\begin{abstract}
With the advent of Industry 4.0, more and more investment casting enterprises are implementing production manufacturing systems, especially in the last two years. This paper summarizes three new common requirements of the digital management aspect in precision casting enterprises, and puts forward three corresponding techniques. They are: the production process tracking card technology based on the main-sub card mode; the workshop site production process processing technology based on the barcode; and the equipment data integration technology. Then, this paper discusses in detail the principle, application and effect of these technologies; to provide the reference for enterprises to move towards digital casting and intelligent casting.
\end{abstract}

Key words: investment casting; digital management; task driven; main-sub card; workshop site processing; data integration

CLC numbers: TP391.9/392/393 Document code: A Article ID: 1672-6421/2016 05-301-09

I $n$ this digital era, digital management plays a vital role in manufacturing and business enterprises with the development of the global economy and the increasing application of information technology in industries and enterprises. Thus, the Chinese government has been implementing more and more policies to enhance the competitiveness of the manufacturing industry by the application of information technology in the hope of accelerating industrialization in China ${ }^{[1]}$. The application of digital management technology in production and business management has been given much attention by more and more enterprises, especially manufacturing enterprises, for effective and strict management can enable good product quality. It is generally accepted that present day IT systems are essential for companies seeking efficiency through organizational integration ${ }^{[2]}$.

Digital management technology is a new technology, which is supported by advanced management methods and information technology. Manufacturing resource planning (MRP II) and enterprise resources planning (ERP) are typical applications of digital management technology. ERP is an evolving concept that supports the need of enterprise-level planning and control of

\section{*Jian-xin Zhou}

Male, born in 1975, Professor. Research interests: casting computer application technology, casting CAE technology and cast ERP system.

E-mail: zhoujianxin@hust.edu.cn.

Received: 2016-01-15; Accepted: 2016-03-20 resources in businesses, and has significantly changed the landscape of business and information technology in many organizations and industries ${ }^{[3-4]}$. The ERP concept has been adopted extensively by manufacturing enterprises and industries ${ }^{[5]}$. ERP systems, software packages that can integrate the organization's processes and functions, are an important resource in the manufacturing and production processes of organizations and enterprises around the world ${ }^{[6-7]}$. In recent years, the 863 Program on computer integrated manufacturing systems (CIMS) has emphasized the studies of core techniques of digital management and ERP software ${ }^{[8]}$. Many techniques of digital management, such as integrated ERP systems, integrated ERP and e-business systems, integrated quality management systems, project management systems, enterprise application integration (EAI) systems, integrated servers/platforms, and the new generation ERP systems have been researched and developed $^{[1]}$.

For nearly 10 years, the author has been engaged in the research and practice of foundry enterprise digitization and informatization ${ }^{[9-10]}$, and helped many precision casting enterprises to build digital management systems (mainly the ERP systems), covering areas from low-end to high-end, including hardware fittings, pump, valve, oil pipe, nuclear power, and aerospace. The successful applications of digital management systems on these casting enterprises have not only strengthened their competitiveness, but also brought many benefits, such as reducing production costs and improving operational 
efficiency. The applications of ERP systems in manufacturing plants help in optimizing manufacturing process flow, which brings about lean manufacturing environment to enterprises ${ }^{[11]}$. It is found that both small and large enterprises are implementing or planning an ERP system in the Australian manufacturing sector ${ }^{[12]}$. In this trend, more and more investment casting enterprises are implementing production manufacturing systems ${ }^{[13-14]}$, especially in recent years. Due to positive impacts of the current "elimination of competition" and "economic downward pressure" phase in the foundry industry, domestic foundry enterprises are faced with great pressure to survive and remain competitive. Moreover, new technologies and innovations should be introduced with the advance of "new normal economy", "Industry 4.0", "intelligent manufacturing" and "Made in China 2025". Without any doubt, digital management systems have been pursued by an increasing number of foundry enterprises. However, the requirements of digital management systems might be different for foundry enterprises due to the differences in manufacturing processes and management processes. In this study, the digital management systems for precision casting enterprises, which make up a significant part of the foundry industry, are mainly analyzed. In the following parts, three new common requirements of the digital management aspect in precision casting enterprises over the past two years are explained in detail.

\section{(1) Production aspect}

The production process tracking card, which is used to record details of each step of a batch of castings in the process of casting production, is also known as the production process card, the construction records card, the production or quality process tracking card. In general, compared with sand casting, precision casting has a larger production batch (although most high valueadded precision castings have single pieces and small batches), a slightly longer production cycle, a smaller size, a lower weight, a slightly higher added value and so on. Precision casting usually uses the batch process card (a card which contains a number of pieces). Precision castings can easily be in chaos in the finishing process, due to frequent reworking and the mixed operations of many sub cards. Therefore, the traditional production process tracking card makes it difficult to track and control the finishing process. Most investment casting enterprises don't use tracking cards after the preparation of the wax model. On the other hand, the information of some tracking process cards is too simple or fixed; lacking of guidance functions for workshop site production. This is a common dilemma that most investment casting enterprises encounter in precision casting production. It is hoped that digital management technology can improve this situation and solve this problem.

\section{(2) Workshop digital aspect}

The "papery plan table" mode is mostly adopted in sand casting production management. For this mode, a papery plan list is firstly made for each working procedure, and then the information is imported to the spreadsheet after the plan list is completed. Thus, the product production progress can be tracked and queried in time. However, precision casting production management uses a "tracking card" mode, and the papery cards record the whole progress from production plan to putting in storage. But if the company wants to track the product production progress in real-time through the software system, the intermediate links often require a lot of manual labor to check and count the schedule on the workshop site, or the company needs to arrange for some staff to transcribe production information on every process card every day. If using a computer terminal, would the inspector or operator could quickly and accurately import production information from the tracking card into the system on the workshop site? The firm management personnel are very concerned about this problem, for their hope is that production process tracking would be very easy.

\section{(3) Quality aspect}

With the deepening of "digital equipment", "intelligent equipment", "equipment interconnection" and other concepts, a new generation of casting equipment basically has input and output data interfaces for external systems to do data interaction. This equipment includes intelligent wax machine, environmental temperature humidity recorder, spectrometer, three-dimensional library, temperature measuring machine, automatic casting machine, heat treatment furnace, etc. On the other hand, the requirements of the large international casting purchasers on casting quality have become more and more strict. Also real quality information obtained from hardware is more convincing.

Combined with the above three common requirements of precision casting enterprise digital management, this paper summarizes the three new technologies developed by our group in the last three years. In the following sections, the principles, application and effect of each technology are explained in detail.

\section{Production process tracking card technology based on main-sub card mode and its application}

The main-sub production process tracking card mode is shown in Fig. 1, from which we can see that the production process tracking card mainly consists of the main and the sub card. The main card consists of the first main card and the second main card. The first main card keeps a record of the information of investment wax pattern preparation section (i.e. wax compression operations before melting), while the second main card keeps track of later finishing section (i.e. all processes after melting). If the precision casting production control node of the enterprise is not too detailed, using the first main card is sufficient as it can cover all the production processes. The first main card can be cast as a module or a same batch of wax compression operations of the same castings, while the second main card can be cast by using molten metal in the same furnace of the same castings and it may correspond to several first main cards. The sub cards, which mainly include circulation sub cards and repair sub cards, are derived from the main card to handle, control tracking card split scene such as cycle operations, and rework and repair operations. In general, one main card can 

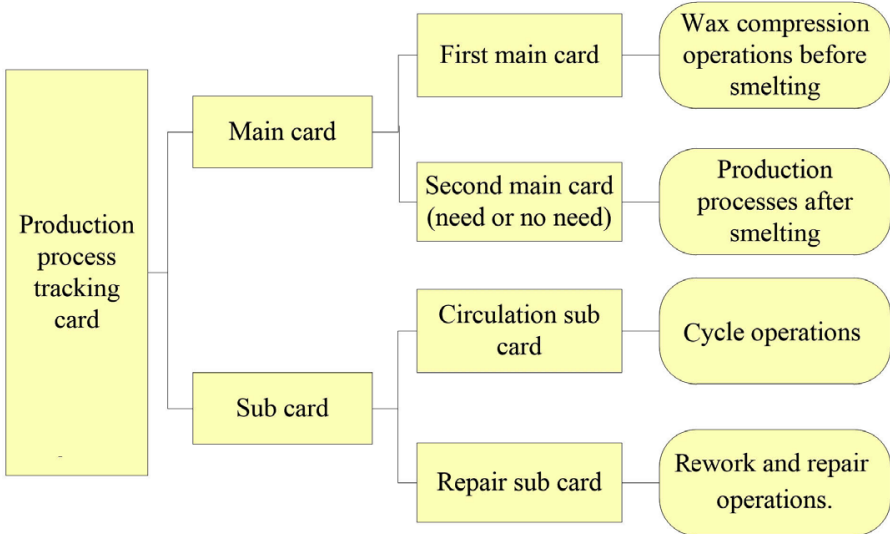

Fig. 1: Main-sub production process tracking card mode

derive from many different sub cards.

As both main cards and sub cards are process tracking cards, five basic aspects of information: namely castings, orders, routing, production and quality information, are included in these process tracking cards. Order information on the card takes the implementation of the special needs of customers directly into production, better than traditional methods that only makes those requirements available for the technical process design. Routing information on the card, which contains production routes and rework routes, varies with different products. It also includes the key indicators or special requirements of process design, the key material quotas and fixed working hours for each process operation, which can make the guidance and supervision of the cards more effective. Production information on the card covers the completed quantity, operators, inspectors, time-consumed, key equipment, and key materials for each production process. The quality information on the card consists of unqualified conditions, number and reasons of each step. Although each process tracking card covers these five aspects of information, the contents of routing, production and quality information, can be different from each other as different process tracking cards have different functions. Each process tracking card has a unique serial number, which is generated in the ERP system according to the batch number of the related process. There are records of the relationship between the piece mark on each casting and the batch numbers of all processes. Therefore, process tracking cards can easily track the production of every casting.

The operation flows of the main-sub production process tracking card, as shown in Fig. 2, are explained in detail as follows:

(1) Make the wax injection plan in ERP system and print out the first main card (as shown in Fig. 3).

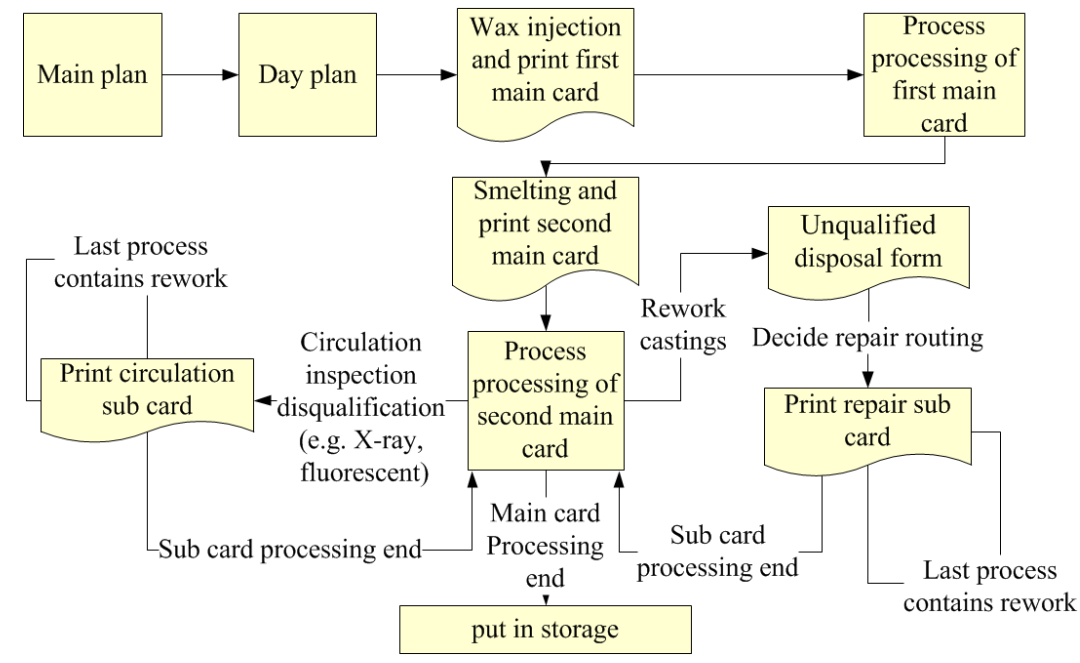

Fig. 2: Operation flow of the main-sub production process tracking card

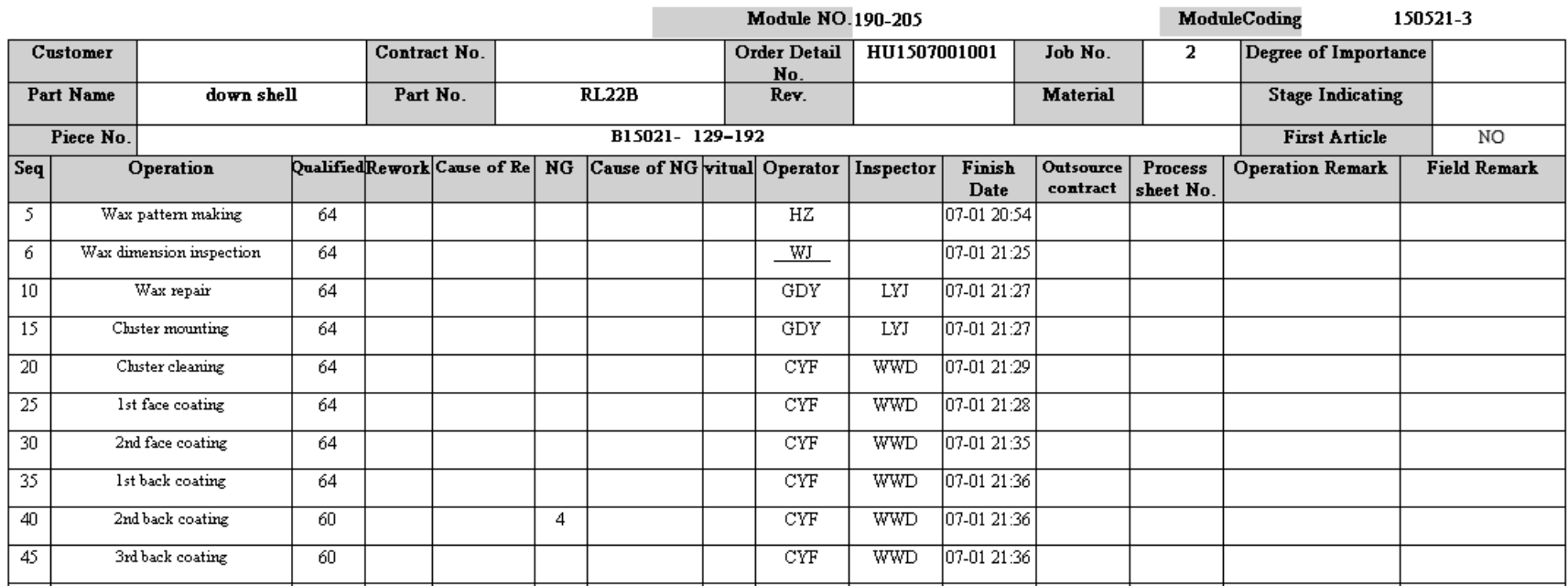

Fig. 3: First main production process tracking card 
(2) Make records of real-time information on the papery card, and perfect the information of the first main card on the ERP system by scanning the barcode on the workshop site terminal.

(3) Make the smelting plan and print out the second main card (as shown in Fig. 4).

(4) Make records of real-time information on the papery card, and perfect the information of the second main card on the ERP system by scanning the barcode on the workshop site terminal.

(5) If disqualifications are found by the circulation inspection operations (e.g. X-ray, fluorescent) in the later finishing stage, make and print out corresponding sub card by scanning the second main card barcode (as shown in Fig. 5).

For example, a second main card contains ten castings. Given that four qualified castings are found in the X-ray inspection operations, the four qualified castings can be entered into the ERP system, while the remaining six unqualified castings should be assigned to a new circulation sub card. The second main card and 4 qualified castings should be placed together, while the sub card and the six unqualified castings should be cycled together. According to the production process of the circulation of unqualified products, make records of real-time information on the papery card and finish production report by scanning the barcode on the circulation sub card. The report of the final step in the sub card (such as X-ray inspection, fluorescence inspections) determines the number of qualified castings and rework-repair castings. If the six castings on the sub card are qualified in the report at the final step, the sub card and six castings will be integrated into the corresponding main card and the four qualified objects. If there are two qualified castings in the sub card, then merge the two qualified objects to the main card, and the remaining four rework castings need to be assigned into another new circulation sub card and then enter a new cycle. The circulation ends when all the castings in the sub card are either qualified or scrapped.

Investment Casting Company

Production Process Tracking Card Second Card-Pouring

R15070100001 2/2p

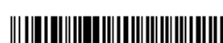

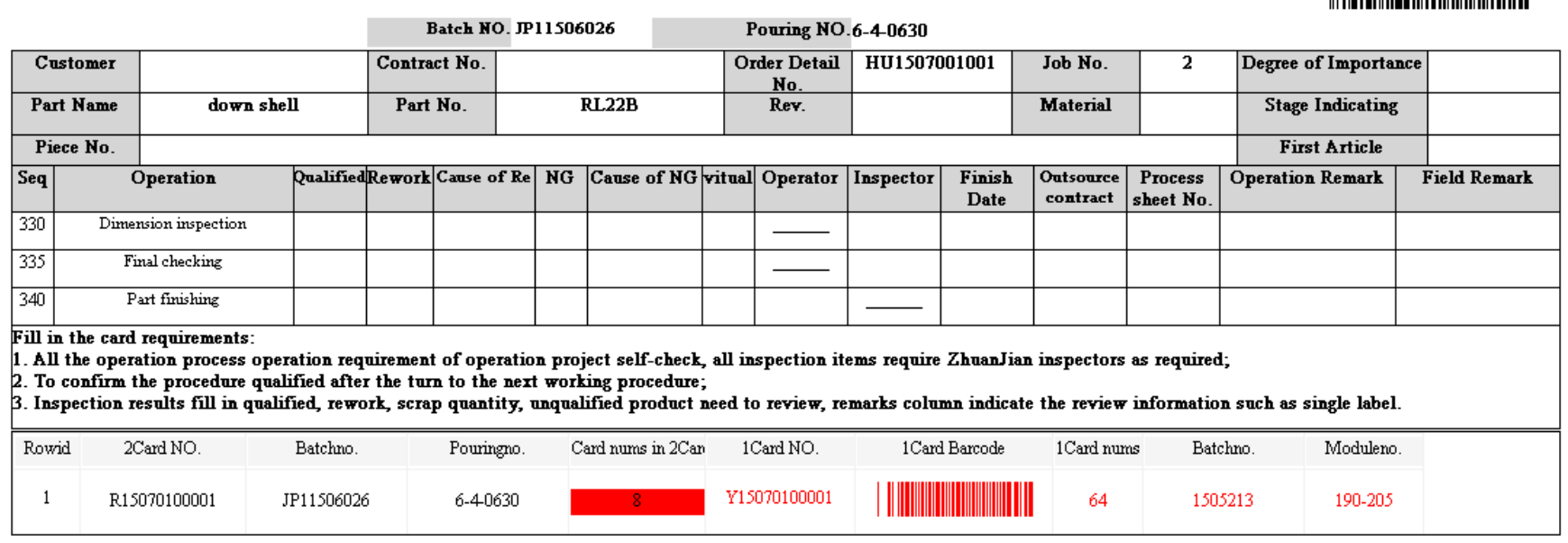

Fig. 4: Second main production process tracking card

Investment Casting Company Production Process Tracking Sub Card

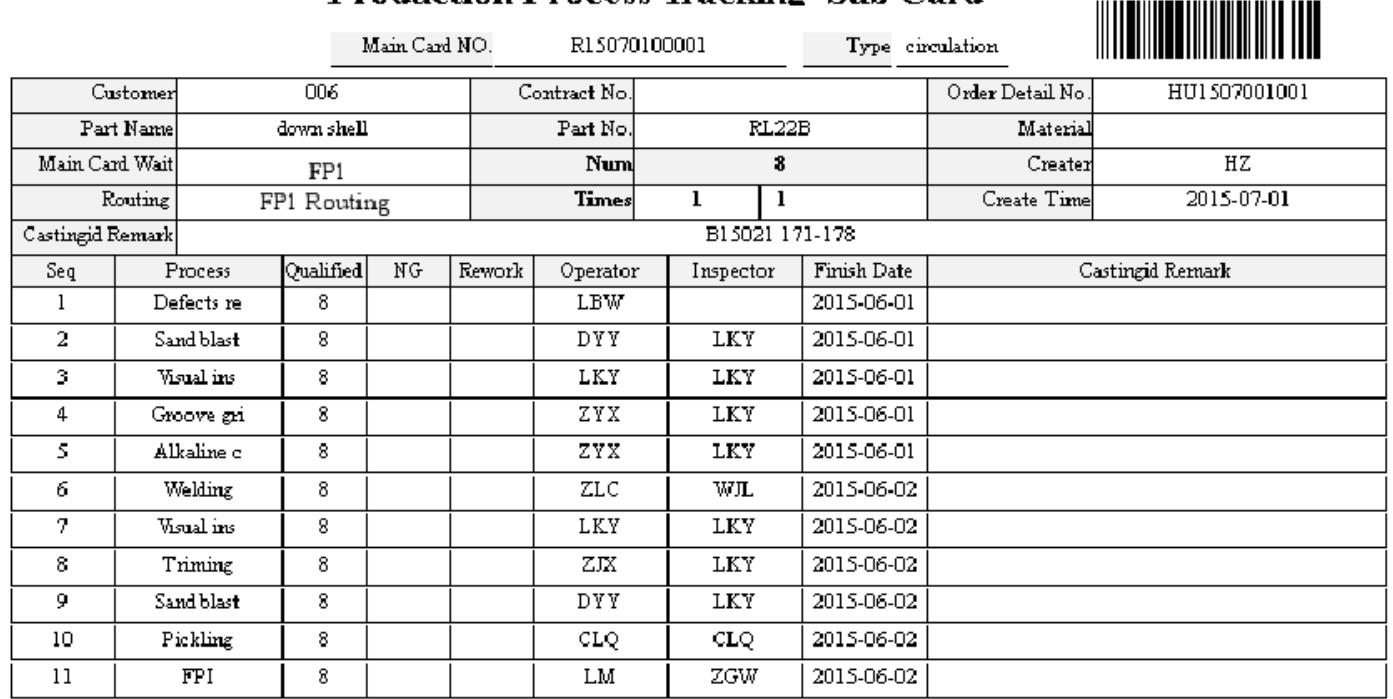

Fig. 5: Circulation sub card 
(6) If there are serious quality problems in a later finishing production process, this requires quality inspecters, personals with responsibility for the production of the products, technician to work together to determine the cause and manner of disposition, you need to scan the barcode in the main card to create the unqualified disposal list. If the disposal result is scrap, scrap them. And if the result requires rework and repair, you need to scan the barcode to create the repair sub card and determine the repair operation route, and then print it out (as shown in Fig. 6). The process of the repair sub card is the same as one of the circulation sub cards.

(7) After the end of production process processing of the second main card, the castings should be put in storage, and all cards of this batch of products will be collected up.

The main-sub card solution of production processes tracking card features the following four principles:

(1) Cards, objects and system information should be consistent, tracking cards flow with the objects on the condition that all data is fedback in the information system.

(2) Sub cards separated from main cards, main cards and qualified objects should be placed together, and sub cards flow with unqualified castings.

(3) Each operation in tracking card could result in feedback many times. However, the next process could result in feedback only when the reporting work of the earlier process (including the sub card) is finished, which ensures the entire card flows together. This is the key point.

(4) In order to guarantee batch management and entire card flow, the quantity that one main card contains should not be too many. If too many, the batch should be divided into several cards to ensure delivery time. How to set the batch number for the tracking card is not explained in this paper.

An application case of the main-sub production process tracking card technology in BM Company (a medium-sized precision casting enterprise, producing titanium alloy castings) is shown in Fig. 3, Fig. 4, Fig. 5 and Fig. 6. Figure 3 shows the first main production process tracking card, and Figure 4 presents the second main production process tracking card. The circulation sub card and the repair sub card are shown respectively in Fig. 5 and Fig. 6. The application of the main-sub tracking card technology has helped the BM Company strengthen functions to guide, record and control of the production process tracking card. It has solved the big problem of workshop site production management - confusion caused by one card being split into many cards. It also helped the casting factory complete the entire process card flow together: batch management as well as recording and tracking the whole production process. In a word, it made on-site management more orderly, and allowed more strict control of the production process according to the process routing. Thus, the quality of products can be guaranteed.

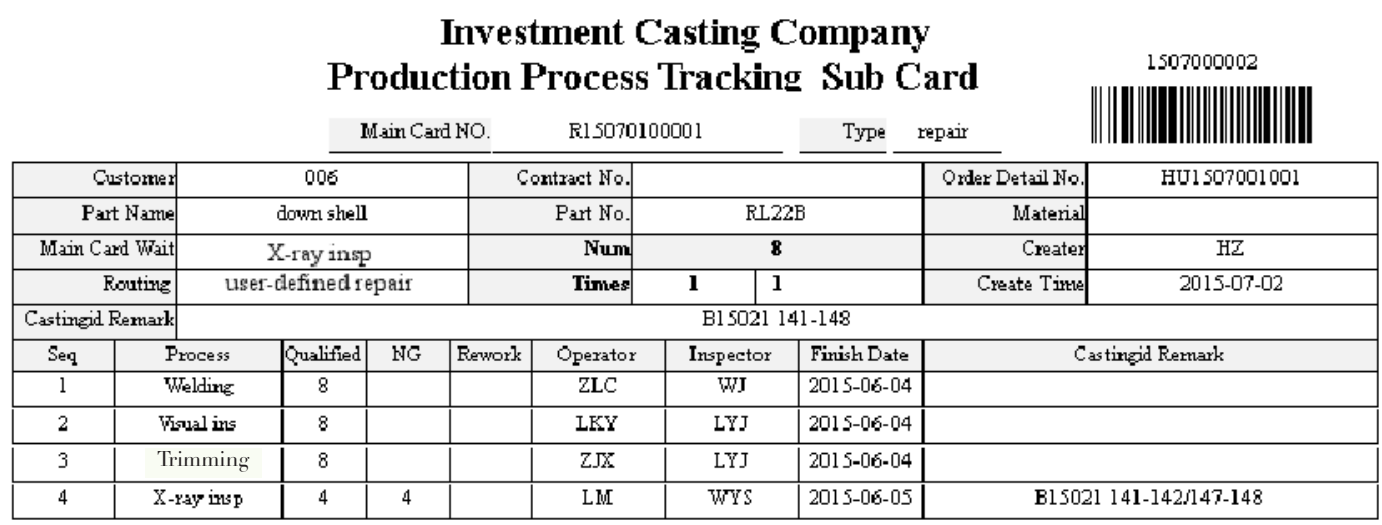

Fig. 6: Repair sub card

\section{Workshop site production process processing technology based on barcode and its application}

The technology path of the workshop site production method processing technology based on barcoding is shown in Fig. 7. Barcode technology makes it easy to type information into the ERP system, as operators can quickly get the corresponding production process tracking card on screen. The details of the technology path are presented as follows:

(1) Print out the papery production process tracking card after making the wax injection or smelting plan.

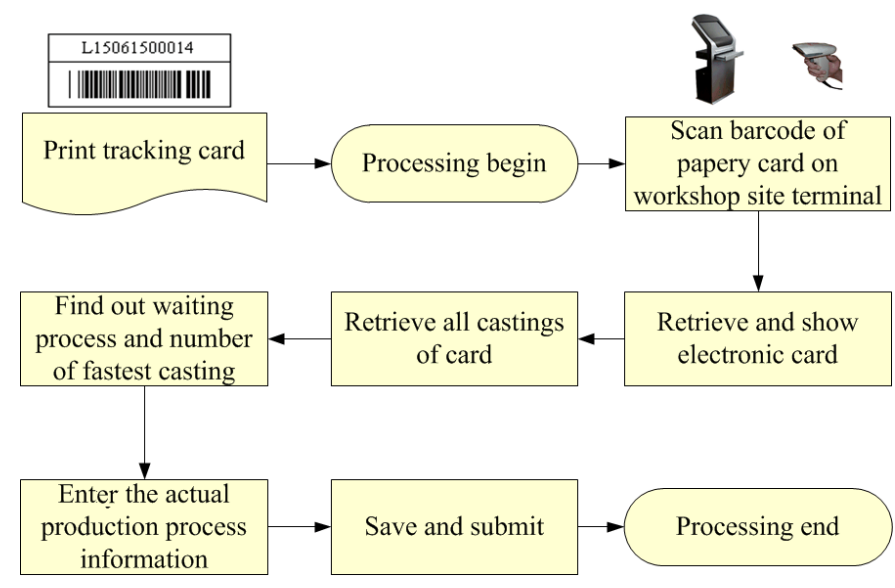

Fig. 7: Technology road of workshop site production process processing technology based on barcode 
The barcode of the plan is generated automatically in the ERP system. There is a one-to-one correspondence between the barcode and the serial number of the card. This records the process information on the papery card according to the actual production condition.

(2) Then, the process processing begins: scan the barcode of the papery card with a barcode gun on the fixed terminals in the workshop, and the electronic tracking card will be shown on the interface of the ERP system (as shown in Fig. 8).

(3) The system will automatically retrieve all information of every casting contained in this card, and find out the waiting process and the number of the fastest progress castings.

(4) Perfect the information in the ERP system according to the papery card (you fill out the left form of interface), and then the information submitted will be shown automatically on the production process tracking card which is on the right of the interface after clicking the save button to submit. The production process information includes personnel, time-consumption, quantity, quality, unqualified, etc. The first process ends and the next process is done the same way.

Figure 8 shows the production processing interface of the card in BM Company. The application of this technology in the BM Company has helped the company strengthen the workshop site management, simplify the production process management by scanning the barcode, gather more comprehensive process information (such as personnel, time-consumption, quantity, quality, unqualified, etc.) by implementing one-time process feedback, reducing much labor in manual transcription and entry, and improving the data accuracy and management efficiency ${ }^{[15-16]}$.

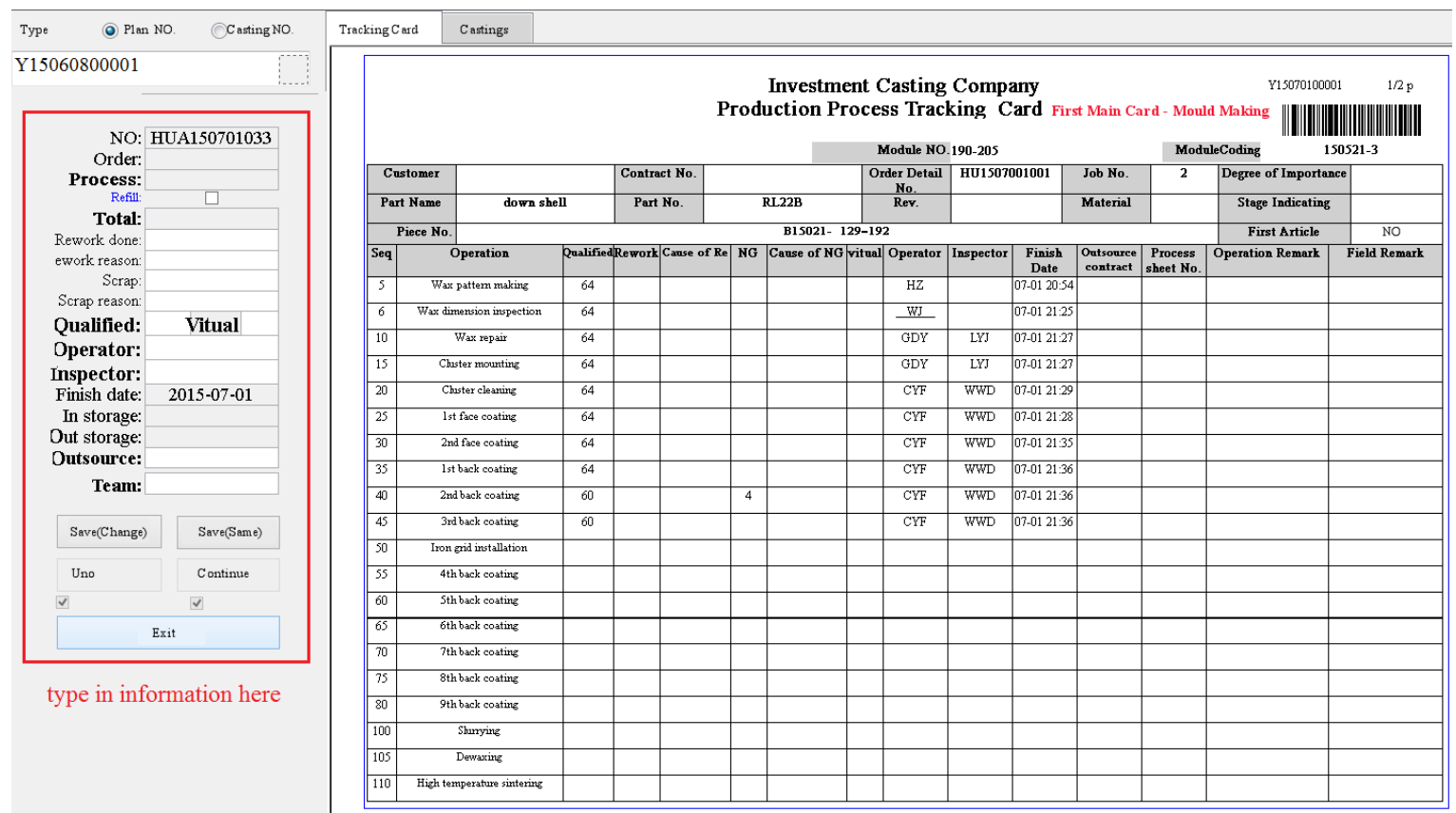

Fig. 8: Production feedback interface of process card

\section{Foundry equipment data integration technology and its application}

The methods of equipment data integration are shown in Fig. 9. According to the intervention, the foundry equipment data integration can be divided into two categories: artificial and nonartificial. The former is divided into afterwards and real-time according to the timeliness; and the latter is divided into entry, import and automatic integration according to the operation mode. This paper mainly discusses the technology to read data from the equipment, not the technology to write data into the equipment (so as to computerize the equipment), because there are fewer casting machines providing the data written interface at present.

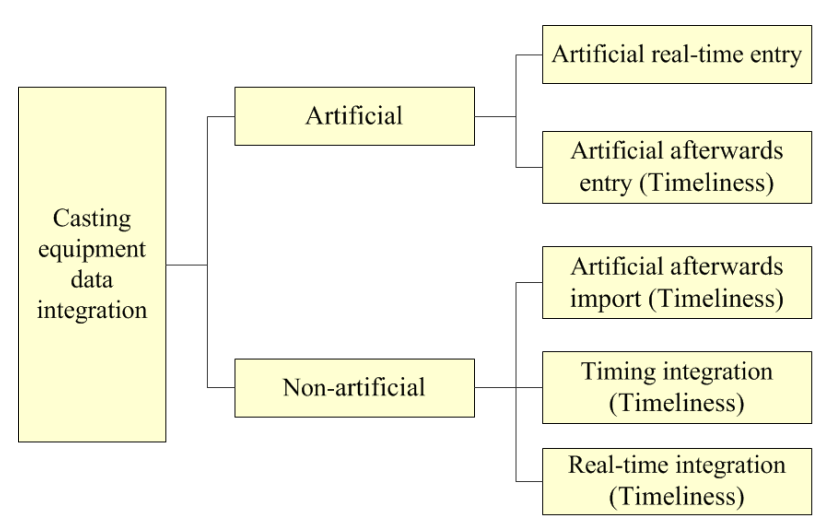

Fig. 9: Methods of equipment data integration 
The technology principle of equipment data integration is shown in Fig. 10. There are several ways for the software system to read the data from the equipment. If the equipment database is open, the data can be read in realtime or timing through the standard database link drive. Otherwise, the data shown on the equipment is firstly recorded on the paper and then the data is typed into the system, or the data is exported as standard data files (e.g. EXCEL file) and then imported into the management.

The application of a direct-reading spectrometer integrated into the ERP system in WH Company (a largesized collective precision casting company) is shown in Fig. 11. The results of chemical analysis can be imported into the ERP system easily and quickly by clicking the "direct reading spectrometer" button. Manual type-in is not needed in the whole process, which can improve the credibility and accuracy of the data. Figure 12 shows the integration application of solid warehouse with ERP system in XZ Company (a medium-sized sand casting company, not investment casting). Figure 13 shows the integration application of the imported spectrometer data. The chemical analysis needs to be saved as an EXCEL file, and then the file is imported into the system, which can save a great deal of manpower and time.

The process of casting production involves many kinds of equipment, such as production equipment, inspection equipment, auxiliary equipment and display equipment. It is heavy but important work to get information from these devices. The equipment that can be integrated with the information system either now or in the future is listed in Table 1. These data integration applications have helped casting enterprises sharply reduce manual copying, recording, and entry data; improving data accuracy and efficiency, and allowing enterprises to gradually move towards digital and intelligent foundry.

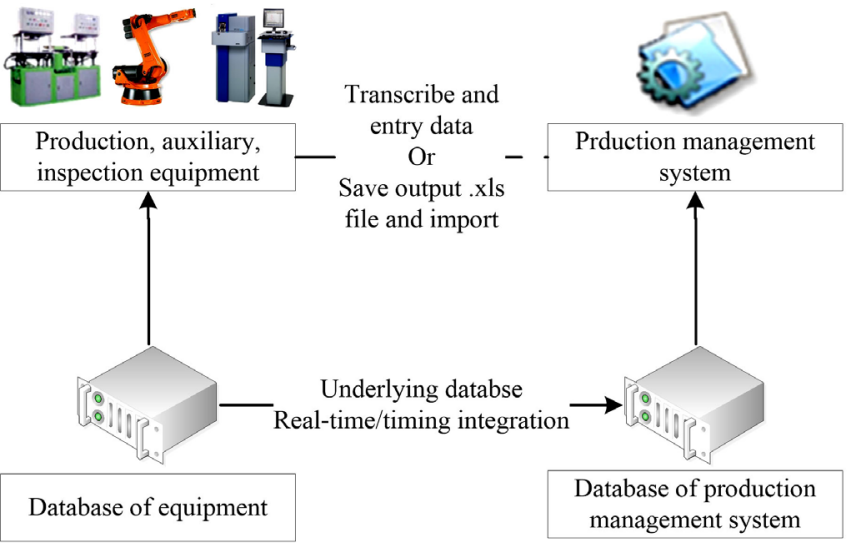

Fig. 10: Technology principle of equipment data integration

Table 1: Equipment that can be integrated with information system either now or in the future

\begin{tabular}{|c|c|c|}
\hline Classification & Equipment name & $\begin{array}{l}\text { Integration } \\
\text { status }\end{array}$ \\
\hline \multirow{3}{*}{ Production equipment } & Core-making machine & No \\
\hline & Wax-making machine & No \\
\hline & Casting machine & No \\
\hline \multirow{2}{*}{ Auxiliary equipment } & Mould solid warehouse & No \\
\hline & Core solid warehouse & Yes \\
\hline \multirow{2}{*}{ Inspection equipment } & Spectrometer & Yes \\
\hline & Thermodetector & No \\
\hline Identification and display & Barcode gun & Yes \\
\hline equipment & Smart terminal & Yes \\
\hline
\end{tabular}

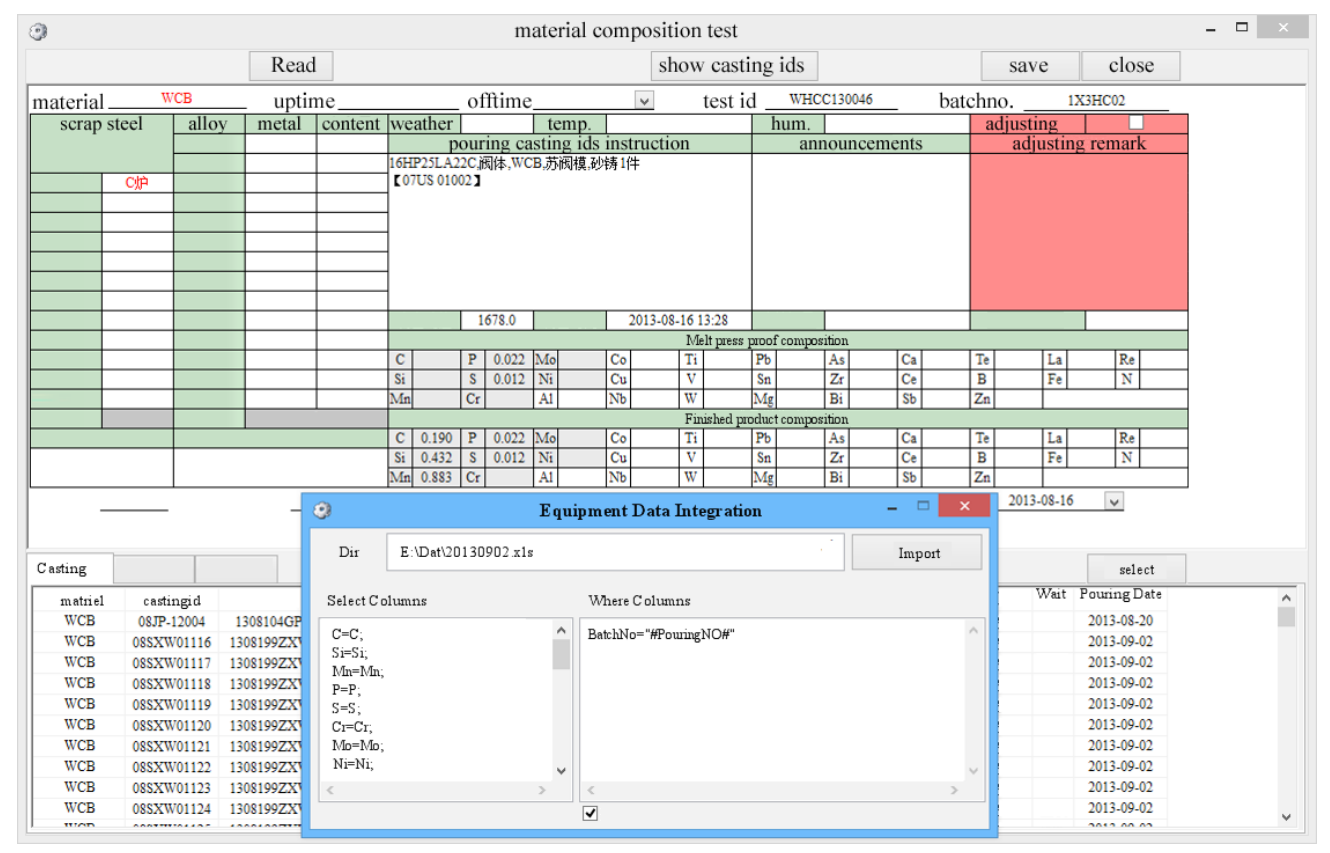

Fig. 11: Integration application of direct reading spectrometer data 


\begin{tabular}{|c|c|c|c|c|c|c|c|c|c|c|c|c|c|}
\hline 团 & & & Auto & atic high-rise & warehouse & ecords & real-tir & & & & & $-\square$ & $x$ \\
\hline Columns(M) Group Analysis & Sint $\mathrm{Ou}$ & t I Filter $(Q$ & trieve Refresh & Tools Exit & & & & & & & & & \\
\hline \begin{tabular}{|l}
$\ldots$ \\
\end{tabular} & & & & & & & & & C: & R:256 & D:0 & $F: 248$ & \\
\hline Work G & Wor & & & & & & [ & & M V & Warehouse-out $v$ & 2015-04 & $v \quad 4$ & 7 \\
\hline$\square$ Groupby 2504 & Row & Recordid & Date & Product & Specification & Location & Quality & SN & Wareh & house-in time $\quad$ V & Warehouse-out time & Time difference & $\wedge$ \\
\hline 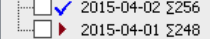 & 1 & 836873 & $2015-0402$ & $1003011 / 6 \mathrm{DF} 1-3$ & 6DF1缸盖 & 6091 & 合格 & 0185-0186 & 2015 & $5-040204: 41$ & 2015-0402 08:09 & 3小时 28 分钟 & \\
\hline & 2 & 836872 & $2015-04-02$ & $1003011 / 6 \mathrm{DF} 1-3$ & 6DF1缸盖 & 1091 & 合格 & 0183-0184 & 2015 & $5-040204: 39$ & $2015-04-0208: 09$ & 3小时 30 分钟 & \\
\hline & 3 & 836871 & $2015-04-02$ & $1003011 / 6 \mathrm{DF} 1-3$ & 6DF1缸盖 & 3091 & 合格 & $0181-0182$ & 2015 & $5-040204: 38$ & 2015-04-02 08:07 & 3小时 29 分钟 & \\
\hline & 4 & 836870 & $2015-0402$ & $1003011 / 6 \mathrm{DF} 1-3$ & 6DF1缸盖 & 6024 & 合格 & $0179-0180$ & 2015 & $-040204: 36$ & 2015-0402 08:06 & 3小时30分钟 & \\
\hline & 5 & 836869 & 2015-0402 & $1003011 / 6 \mathrm{DF} 1-3$ & 6DF1缸盖 & 2091 & 合格 & $0177-0178$ & 2015 & $5-040204: 34$ & 2015-0402 08:05 & 3小时31分钟 & \\
\hline & 6 & 836868 & $2015-0402$ & $1003011 / 6 \mathrm{DF} 1-3$ & 6DF1缸盖 & 3024 & 合格 & $0175-0176$ & 2015 & $5-040204: 33$ & 2015-0402 08:03 & 3小时30分钟 & \\
\hline & 7 & 836867 & $2015-0402$ & $1003011 / 6 \mathrm{DF} 1-3$ & 6DF1缸盖 & 5042 & 合格 & 0173-0174 & 2015 & $-040204: 32$ & 2015-0402 08:05 & 3小时33分钟 & \\
\hline & 8 & 836866 & $2015-0402$ & $1003011 / 6 \mathrm{DF} 1-3$ & 6DF1缸盖 & 5071 & 合格 & $0171-0172$ & 2015 & $5-040204: 30$ & 2015-04-02 08:01 & 3小时 31 分钟 & \\
\hline & 9 & 836865 & $2015-0402$ & $1003011 / 6 \mathrm{DF} 1-3$ & 6DF1缸盖 & 2024 & 合格 & $0169-0170$ & 2015 & 5-0402 03:41 & 2015-04-02 08:03 & 4小时22分钟 & \\
\hline & 10 & 836864 & $2015-0402$ & $1003011 / 6 \mathrm{DF} 1-3$ & 6DF1缸盖 & 4024 & 合格 & $0167-0168$ & 2015 & $-040203: 40$ & $2015-040208: 01$ & 4小时 21 分钟 & \\
\hline & 11 & 836863 & $2015-0402$ & $1003011 / 6 \mathrm{DF} 1-3$ & 6DF1缸盖 & 5081 & 合格 & $0165-0166$ & 2015 & $-040203: 39$ & $2015-04-0207: 57$ & 4小时 18 分钟 & \\
\hline & 12 & 836862 & $2015-04-02$ & $1003011 / 6 \mathrm{DF} 1-3$ & 6DF1缸盖 & 2042 & 合格 & $0163-0164$ & 2015 & $-040203: 37$ & $2015-040207: 59$ & 4小时 22 分钟 & \\
\hline & 13 & 836861 & $2015-0402$ & $1003011 / 6 \mathrm{DF} 1-3$ & 6DF1卸盖 & 4042 & 合格 & $0161-0162$ & 2015 & $5-04: 0203: 36$ & $2015-04-0207: 59$ & 4小时 23 分钟 & \\
\hline & 14 & 836860 & $2015-0402$ & $1003011 / 6 \mathrm{DF} 1-3$ & 6DF1缸工盖 & 6081 & 合格 & $0159-0160$ & 2015 & $5-040203: 35$ & $2015-04-0207: 56$ & 4小时 21 分钟 & \\
\hline
\end{tabular}

Fig. 12: Integration application of real-time reading automatic high-rise warehouse data

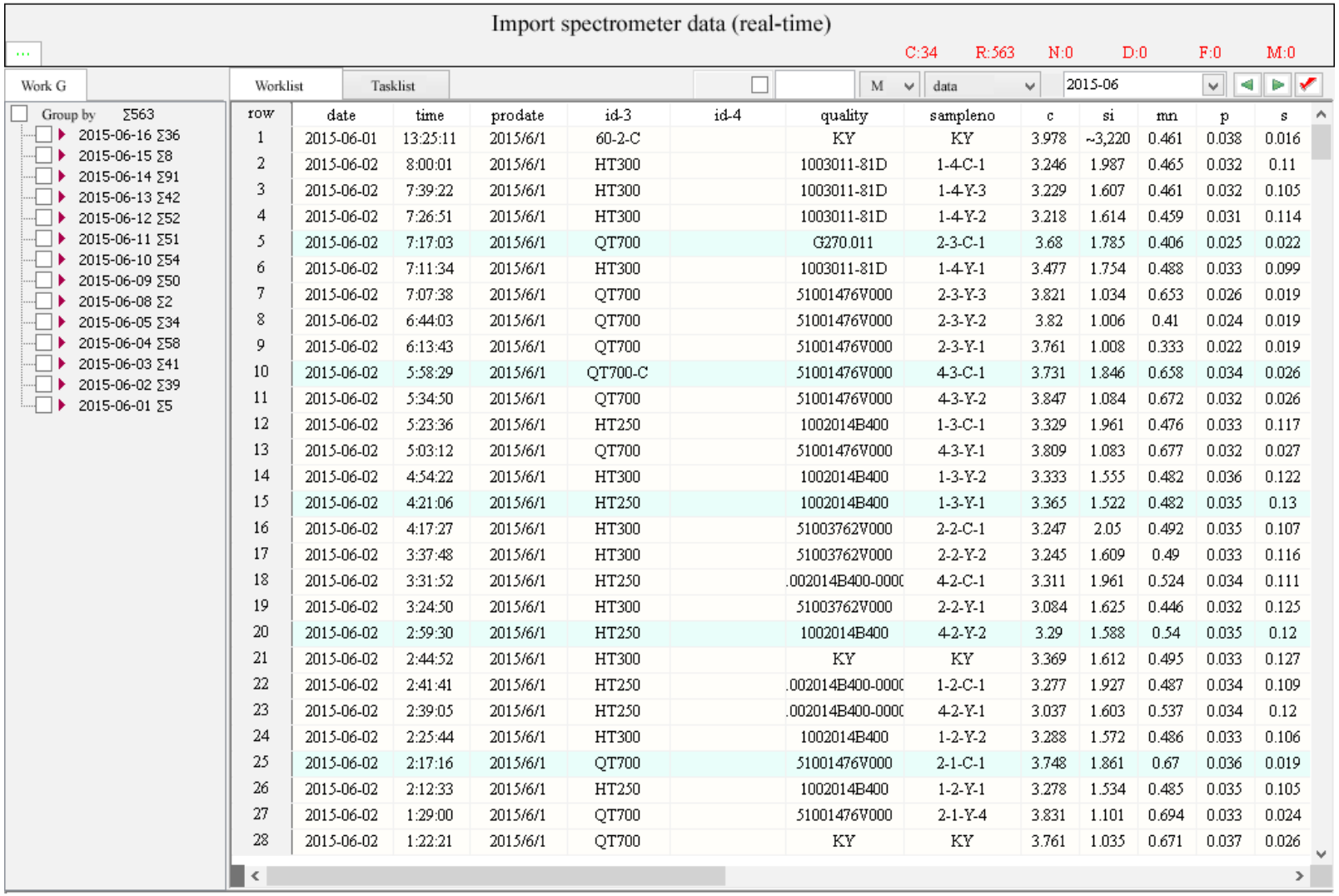

Fig. 13: Integration application of afterwards import spectrometer data

\section{Conclusions}

This paper summarizes three new common requirements of the digital management aspect in precision casting enterprises, and discusses three corresponding techniques proposed by our group in the research on the digital management of precision casting enterprises in the last three years. It provides a reference for enterprises to move towards digital casting, or, intelligent casting. The main contents are summarized as follows:
(1) Discussing the principle and application of the production process tracking card technology based on the main-sub card mode. The technology can help enterprises to strengthen the functions to guide, record and control the production process tracking card; and solve process card splits, process confusion and other problems, making workshop site management more orderly. It can also help factories to complete the entire process card flow together: batch management as well as the recording and tracking of the whole production process. 
(2) Discussing the principle and application of the workshop site production process processing technology based on the barcode. The technology can help enterprises to strengthen the workshop site management, and simplify the production process management by scanning the barcode. It can also gather more comprehensive process information by only one time process feedback, reduce much work of manual transcription and entry, and improve the data accuracy and management efficiency

(3) Discussing the principle and application of the casting equipment data integration technology. The technology can help investment casting enterprises sharply reduce manpower of copying, recording, and entry data; improving efficiency, and allowing enterprises to gradually move towards a digitally intelligent foundry.

Against the background of "Industry 4.0", "smart casting", "made in China 2025", the future of casting is destined to pursue digital casting and intelligent casting. Compared to sand casting, die-casting and other production methods, the precision casting with more high-end and higher information level will take the lead in starting and deepening digital and intelligent foundry management. Investment casting will push the application of digital management to a broader, deeper prospect, and give birth to more advanced technologies.

\section{References}

[1] Xu X F, Zhang L, Li Y, et al. Digital enterprise management in China: current status and future development. International Journal of Production Research, 2005, 43(12): 2593-2601.

[2] Powell D, Riezebos J, and Strandhagen J O. Lean production and ERP systems in small and medium-sized enterprises: ERP support for Pull Production. International Journal of Production Research, 2013, 51(2): 395-409.

[3] Jacobs $F$ and Bendoly $E$. Enterprise resource planning: Developments and directions for operations management research. European Journal of Operational Research, 2003, 146(2): 233-240.

[4] Jacobs F and Weston F C Jr. Enterprise resource planning (ERP): a brief history. Journal of Operations Management, 2007 , 25(2): 357-363.
[5] Olson D L, Chae B K, Sheu C. Relative impact of different ERP forms on manufacturing organisations: an exploratory analysis of a global manufacturing survey. International Journal of Production Research, 2013, 51(5): 1520-1534.

[6] Ram J, Corkindale D, and Wu M. Implementation critical success factors (CSFs) for ERP: Do they contribute to implementation success and post-implementation performance? International Journal of Production Economics, 2013, 144(1): 157-174.

[7] Ifinedo P and Olsen D H. An Empirical Research on the Impacts of organisational decisions' locus, tasks structure rules, knowledge, and IT function's value on ERP system success. International Journal of Production Research, 2015, 53(8): 2554-2568.

[8] Xu X F. Developing status, tendency and consideration on ERP technology. Manuf. Inform. Eng., 2003, 32: 19-29.

[9] Zhou Jianxin, Ji Xiaoyuan, Liao Dunming, et al. Research and application of enterprise resource planning system for foundry enterprises. China Foundry, 2013, 10(1): 8-17.

[10] Ji Xiaoyuan. Research on the Single-piece Management Method, Intelligent Method and Their Applications in Foundry Informatization. Dissertation, Huazhong University of Science and Technology, Wuhan, China, 2013. (In Chinese)

[11] Kong P and Daud Y. Effectiveness of Enterprise Resource Planning System in Supporting the Lean Manufacturing. Applied Mechanics and Materials, 2013, 315: 899-904.

[12] Hasan M, Trinh N, Chan F, et al. Implementation of ERP of the Australian manufacturing companies. Industrial Management \& Data Systems, 2011, 111(1): 132-145.

[13] Jiang Buju, Lu Zhigang, and Zhou Zeheng. Development of Investment Casting in China. Special Casting \& Nonferrous Alloys, 2009(12): 1132-1136. (In Chinese)

[14] Ji Xiaoyuan, Zhou Jianxin, Yin Yajun, et al. Research on the Digital and Intelligent Casting Technology and Its Application in Casting Enterprise. In: Proceedings of 2014 China Foundry Week, 2014: 1-14. (In Chinese)

[15] Jiang Hai. Research and application on management system for the production of mechanical parts based on bar code technology in foundry enterprises. Dissertation, Huazhong University of Science \& Technology, Wuhan, China, 2014. (In Chinese)

[16] Zhou Jianxin, Yang Hu, and Ji Xiaoyuan. Research on production schedule online processing management of sand casting workshop based on single piece management model. Advanced Materials Research, 2014, 1037: 499-505. 